\title{
OZONE LIDAR OBSERVATIONS IN THE CITY OF PARIS: SEASONAL VARIABILITY AND ROLE OF THE NOCTURNAL LOW LEVEL JET
}

\author{
Gérard Ancellet $^{1 *}$, François Ravetta ${ }^{1}$, Jacques Pelon ${ }^{1}$, Andrea Pazmino ${ }^{1}$, Amélie Klein ${ }^{1}$, Elsa \\ Dieudonné$^{2}$, Patrick Augustin ${ }^{2}$, Hervé Delbarre ${ }^{2}$ \\ ${ }^{1}$ Laboratoire Atmosphere Milieux, Observations Spatiales (LATMOS), CNRS-INSU, Sorbonne \\ Université,Université Versailles St Quentin, Paris, France \\ ${ }^{2}$ LPCA Université du Littoral-Côte d'Opale, Dunkerque, France \\ *Email: gerard.ancellet@latmos.ipsl.fr
}

\begin{abstract}
Ozone lidar measurements have been carried out in Paris during 4 years to characterize the seasonal variability of the vertical gradient within the urban planetary boundary layer (PBL). The interaction between $\mathrm{NO}_{\mathrm{x}}$ emission and thermal stability of the PBL is the main driver of the winter strong positive $\mathrm{O}_{3}$ gradient, while summer neutral gradient is related to weaker thermal stability and photochemical ozone production at the regional scale. Simultaneous lidar measurements of ozone and wind vertical profiles during 36 hours in September 2014 also show that the nocturnal low level jet (NLLJ) plays a significant role in the early morning ozone increase.
\end{abstract}

\section{INTRODUCTION}

Understanding the behavior of ozone in the urban boundary layer is necessary to develop effective air pollution control strategies in cities throughout the world. A key uncertainty in understanding ground level ozone is knowledge of the role of vertical and regional transport processes in controlling ozone and ozone precursors mixing and dispersion Chemical and physical processes at night and during transitions (night-to-day and dayto-night) as well as lack of vertically resolved measurements limit our ability to forecast "nextday” ozone concentrations [1].

\section{METHODOLOGY AND EXPERIMENTAL SETUP}

\subsection{Objectives and methodology}

Assessment of the UV DIAL lidar observations to improve our knowledge of ozone transport and photochemistry in the urban boundary layer was made using (1) regular measurements of the $\mathrm{O}_{3}$ vertical profile between $0.3 \mathrm{~km}$ and $3 \mathrm{~km}$ (4-8 times per month) in Paris city center to characterize the seasonal evolution of ozone vertical gradient within and above the urban planetary boundary layer (PBL) (2) continuous observations of $\mathrm{O} 3$ and wind vertical profiles and of PBL height during 48 hours. The seasonal cycle was studied using lidar measurements averaged over 1hour during daytime and with partial clear sky conditions up to $3 \mathrm{~km}$ altitude. Such measurements are available during 4 years (20112014) with 4-8 profiles per month [2]. Regarding the analysis of the $\mathrm{O} 3$ vertical profile diurnal cycle, a specific campaign was held in Paris in September 2014 [3].

\subsection{The ozone lidar observations}

The ozone Differential Absorption Lidar (DIAL) instrument is an airborne lidar system $[4,5]$ installed in a shelter at Sorbonne Université (SU) in the frame of the QUALAIR facility. The transmitter module is based on a solid state Nd-YAG laser and Stimulated Raman Scattering in deuterium to generate 3 wavelengths $(266,289$, and $316 \mathrm{~nm})$. The wavelength pair $266-289 \mathrm{~nm}$ is used for the ranges between $0.4 \mathrm{~km}$ and $1.7 \mathrm{~km}$, while measurements with the pair $289-316 \mathrm{~nm}$ provide data above $1.5 \mathrm{~km}$ only. The Lidar vertical resolution varies from $100 \mathrm{~m}$ at the $0.4 \mathrm{~km}$ altitude to $1000 \mathrm{~m}$ at the $3 \mathrm{~km}$ altitude. The temporal resolution can be as low as 2 minutes, but only hourly profiles are considered for the analysis of the seasonal variability. In the altitude range $200 \mathrm{~m}$ to $3000 \mathrm{~m}$ the Lidar accuracy including the different error sources (signal to noise ratio, Lidar alignment, background signal correction) is of the order of $15 \mu \mathrm{g} \cdot \mathrm{m}^{-3}$. At range below $500 \mathrm{~m}$, the DIAL measurement is mainly limited by the geometrical telescope overlap function uncertainty. To further reduce the error on the ozone measurements below $500 \mathrm{~m}$ a new optical receiver has been added 
in October 2013 to the Lidar. It includes a $10 \mathrm{~cm}$ telescope with a $3.3 \mathrm{mrd}$ field of view to reach a full overlap near $200 \mathrm{~m}$. Measurements are alternately made using the large $40 \mathrm{~cm}$ telescope in the far field from $400 \mathrm{~m}$ to $3 \mathrm{~km}$ and using the small near field telescope from $200 \mathrm{~m}$ to $900 \mathrm{~m}$. For the near field measurements, only two wavelengths (266 and 289nm) are necessary because the 266nm Lidar signal is still strong enough below $1 \mathrm{~km}$. The correlation between the surface measurements at the Eiffel Tower (310m ASL) and the Lidar data averaged between $250 \mathrm{~m}$ and $500 \mathrm{~m}$ high have been used to check the Lidar accuracy at $310 \mathrm{~m}$. The comparison with the far field ozone

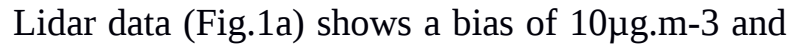
a $14 \mu \mathrm{g} . \mathrm{m}-3$ standard deviation. When using the near field mode (Fig.1b) the bias is close to zero and the standard deviation is $7 \mu \mathrm{g} . \mathrm{m}-3$.
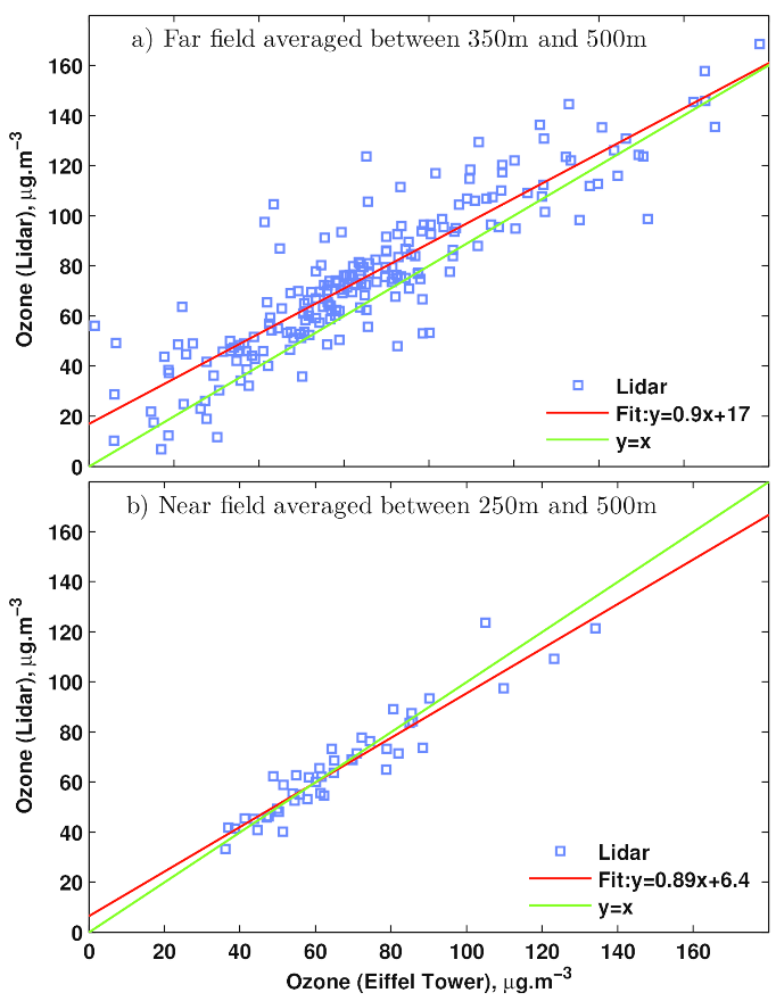

Fig. 1: Scatter plot of ozone concentrations measured by the Lidar and the Eiffel Tower measurements between 2011 and 2014. Top panel shows the Lidar far field (large telescope) averaged between $350 \mathrm{~m}$ and $500 \mathrm{~m}$ and the bottom panel shows the Lidar near field (small telescope) averaged between $250 \mathrm{~m}$ and $500 \mathrm{~m}$.

\subsection{The wind and backscatter lidar data}

Wind fields during the September 2014 campaign were measured using an eye safe scanning wind Lidar (Leosphere Windcube WLS 100) operating at $1.54 \mu \mathrm{m}$ with a repetition rate of $10 \mathrm{kHz}$. The Doppler shift is measured with a heterodyne technique. The wind Lidar was located on the roof of a $60 \mathrm{~m}$ tower providing wind fields in the range 0.19 to $1.5 \mathrm{~km}$ with a $50 \mathrm{~m}$ resolution [6]. The wind lidar accuracy is of the order of $0.5 \mathrm{~m} . \mathrm{s}^{-1}$. The QUALAIR operational eye safe micropulse Lidar emitting at $532 \mathrm{~nm}$ is also used to monitor the aerosol backscatter profile with a $15 \mathrm{~m}$ vertical resolution and a 1s time resolution. The PBL height is calculated using the wind variance maximum during the night and the day-to-night and night-to-day transitions, while during the day the altitude is taken when the variance of the backscatter lidar is maximum [7].

\subsection{Surface Data}

The Paris air quality network provides $\mathrm{O}_{3}, \mathrm{NO}_{2}$ surface concentrations at about 70 stations. Two stations have been selected for our study: first at the top of the Eiffel Tower (275m AGL) and second at ground level away from direct traffic emission (Paris 13). Temperature lapse rate between the Montsouris station and the top of the Eiffel tower is also used to characterize the atmospheric thermal stability. The tropospheric column of $\mathrm{NO}_{2}$ is measured by SAOZ (Système d'Analyse par Observation Zénithale) instrument. Although SAOZ was developed to monitor $\mathrm{NO}_{2}$ total columns, it can also infer tropospheric columns in the polluted urban PBL $[8,9]$.

\section{RESULTS}

\subsection{The seasonal cycle of the ozone vertical gradient}

The seasonal average and median of the vertical profiles of ozone measured by the LIDAR between $250 \mathrm{~m}$ and $3 \mathrm{~km}$ are shown in Fig. 2 for the entire measurement period (2011-2014). The ozone gradients within the PBL are the largest in winter $\left(60 \mu \mathrm{g} \cdot \mathrm{m}^{-3} \cdot \mathrm{km}^{-1}\right)$ and fall $\left(40 \mu \mathrm{g} \cdot \mathrm{m}^{-3} \cdot \mathrm{km}^{-1}\right)$, while it is minimum in spring $\left(27 \mu \mathrm{g} \cdot \mathrm{m}^{-3} \cdot \mathrm{km}^{-1}\right)$ and summer $\left(20 \mu \mathrm{g} \cdot \mathrm{m}^{-3} \cdot \mathrm{km}^{-1}\right)$. The positive gradients are still visible using the quartiles, meaning that the result is robust. The seasonal variability of the 
$\mathrm{O}_{3}$ gradients in the urban layer near the surface shows a similar pattern when using the surface and Eiffel tower observations, but with lower values 25 and $14 \mu \mathrm{g} \cdot \mathrm{m}^{-3} \cdot \mathrm{km}^{-1}$ respectively in winter fall and less than $1 \mu \mathrm{g} \cdot \mathrm{m}^{-3} \cdot \mathrm{km}^{-1}$ in spring and summer. In winter, the amount of ozone destruction needed to explain an ozone positive gradient of $60 \mu \mathrm{g} \cdot \mathrm{m}^{-3} \cdot \mathrm{km}^{-1}$ between $60 \mathrm{~m}$ and $590 \mathrm{~m}$ is of the order of $8 \mathrm{mg} \cdot \mathrm{m}^{-2}$, in good agreement with the winter $\mathrm{NO}_{2}$ column measured by the SAOZ.

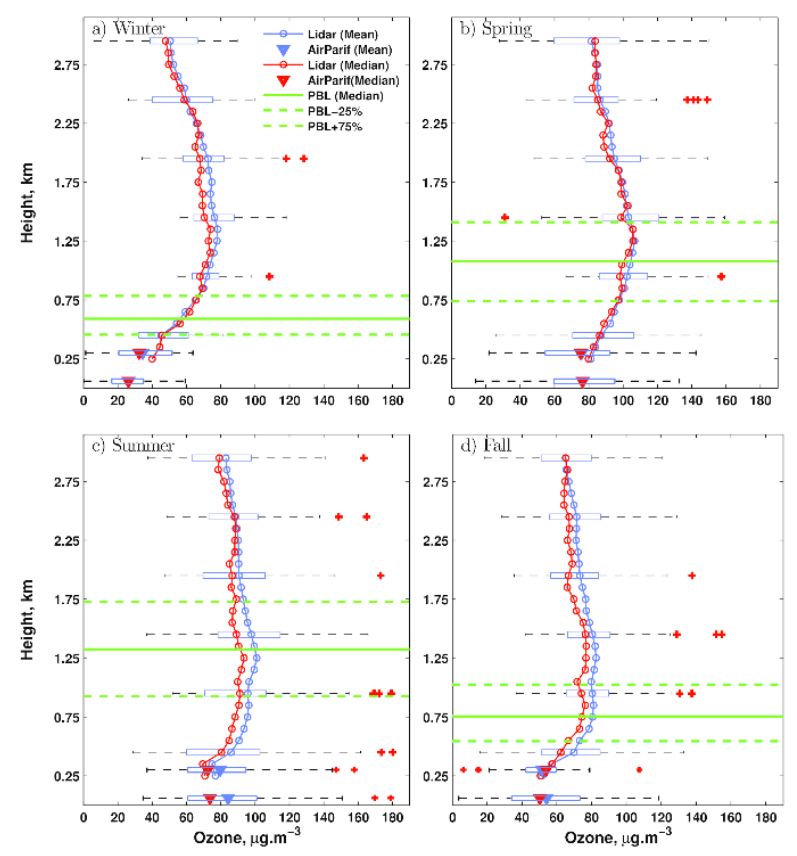

Fig. 2 Seasonal variation (a to d) of vertical profiles of ozone for the period 2011-2014. Blue (red) curves are the mean (median) of vertical ozone profiles for each season. Blue (red) triangles are the corresponding ozone seasonal mean (median) for in-situ measurements at the surface and at the Eiffel Tower. Whisker boxes limits show the interquartile range whereas outliers are showed by red markers. Planetary boundary layers (PBL) heights are represented by a green continuous line while the dashed green lines are for the percentiles $25 \%$ and $75 \%$.

For spring and summer, ozone is well-mixed in the first $300 \mathrm{~m}$, but there is still a weak positive gradient above $500 \mathrm{~m}$. The spring and summer ozone gradients in the upper part of the PBL are however less visible when using the values of the 75th percentile. Considering the seasonal variability of the thermal gradient, we expect a neutral vertical ozone gradient in the urban layer up to
$300 \mathrm{~m}$ in summer. Considering that the level of $\mathrm{NO}_{2}$ column $6 \mathrm{mg} \cdot \mathrm{m}^{-2}$ ) is still significant in summer to induce a positive gradient across the PBL, it means that photochemical production at the scale of the Paris area and vertical mixing are strong enough to compensate for this $\mathrm{NO}_{2}$ titration in summer.

\subsection{The role of the nocturnal boundary layer jet on the surface ozone diurnal cycle}

A campaign was held in Paris to study the role of the nocturnal low level jet (NLLJ) on the ozone diurnal cycle. Vertical ozone profiles were measured during a 36 hour intensive observation period (IOP) on 9-10 September 2014.

Ozone measurements from the Lidar are combined with in-situ measurements at the surface (Paris13) and at the Eiffel Tower (275m AGL) in one ozone contour plot (Fig.3a). Ozone Lidar measurements can be as low as 200m AGL, when using the near field telescope. The PBL height in Fig. 3 is calculated as described in Section 2.3. During the IOP, low nocturnal boundary layer (NBL) heights are observed, with values $\sim 250 \mathrm{~m}$ AGL. Ozone values are vertically homogeneous within the PBL during daytime due to strong vertical mixing during daytime as shown by the Doppler lidar vertical wind speeds (Fig. 3d). Ozone values are also larger in the afternoon in good agreement with the peak in the photochemical ozone production from NOx and VOCs emissions. During the night, $\mathrm{O}_{3}$ concentrations are above $100 \mu \mathrm{g} . \mathrm{m}^{-3}$ on 9 Sept., whereas they are as low as $40 \mu \mathrm{g} . \mathrm{m}^{-3}$ late in the night/early morning on 10 Sept. This feature just above the NBL is co-located with a NLLJ, (Fig. 3b).The horizontal wind direction and air mass transport modelling (not shown) shows the NLLJ on 10 Sept. 2014 originates from a region with low ozone production northeast of Paris. Potential temperature and $\mathrm{O}_{3}$ gradients have positive values during the night, corresponding to a stable NBL (Fig. 3b). Due to the stable NBL, ozone is trapped close to the surface and $\mathrm{O}_{3}$ deposition combined with titration by NO result in a positive ozone gradient [10]. On 10 Sept.2014, the NBL lapse rate $\left(+5 K \cdot \mathrm{km}^{-1}\right)$ is however two times lower than the temperature gradient on 9 Sept., which favors vertical transport and mixing of the low ozone layer downwards. The 
temporal evolution of $\mathrm{NO}_{2}$ at the surface and the Eiffel tower (Fig. 3e) also shows that at early morning $\mathrm{NO}_{2}$ gradient (06:00-08:00 LT) is higher on 9 Sept. than on 10 Sept. while emissions are expected to be the same. Increased vertical transport due to the NLLJ between the residual layer (RL) and the NBL is the most likely explanation for the ozone decrease in the RL. Enhanced nocturnal vertical mixing associated with NLLJs has already been observed in similar cases [1, 11]. The low ozone concentration in the RL has also consequences on the next day rate of ozone increase near the surface (Fig. 3a). Indeed the rate of increase between 10:30-12:30 LT is only $12 \mu \mathrm{g} . \mathrm{m}^{-}$ ${ }^{3} \cdot \mathrm{h}^{-1}$ on 10 Sept. while it is $26 \mu \mathrm{g} \cdot \mathrm{m}^{-3} \cdot \mathrm{h}^{-1}$ on 9 Sept. [3].

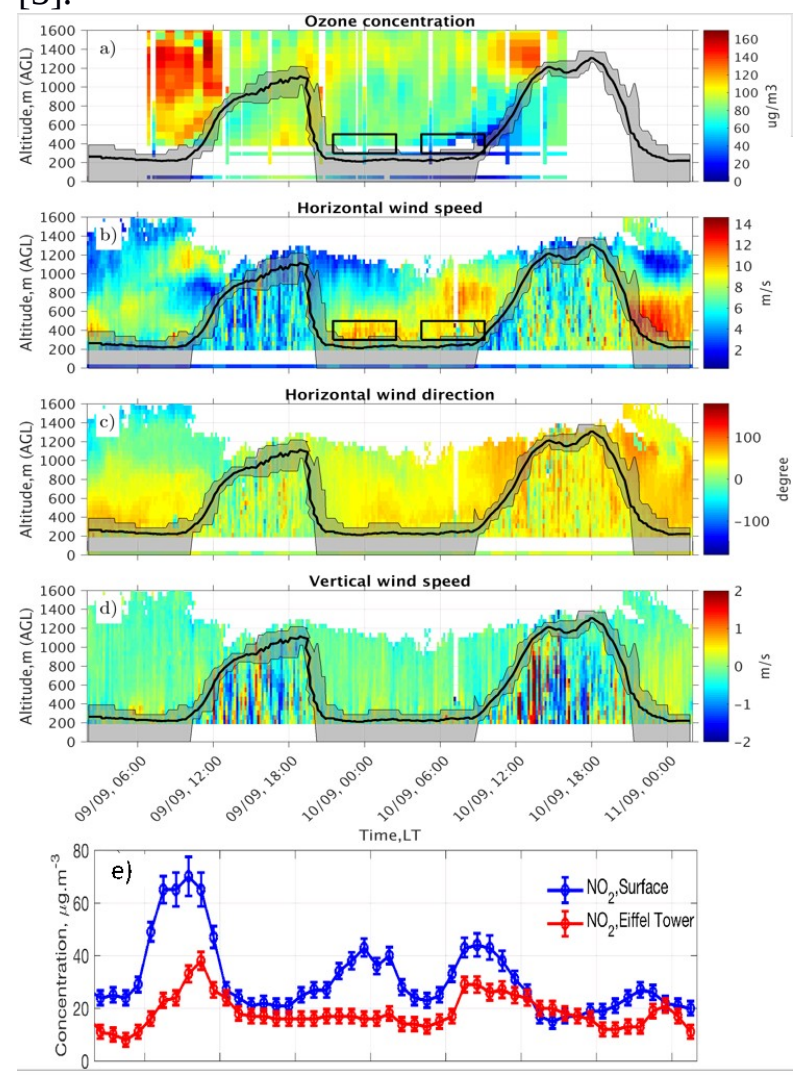

Fig. 3:Time evolution on 9 and 10 September of lidar O3 concentrations (a), of surface O3 (a) and $\mathrm{NO}_{\mathrm{x}}$ (e) measured at the Eiffel Tower (275m AGL) and the Paris13 station (5m AGL), of the horizontal lidar wind speed (b) and direction (c), of vertical wind speed (d). Surface wind speed and direction measured at Montsouris are also shown in (b) and (c). The PBL height is shown in black with its uncertainty in grey.

\section{Conclusion and Perspectives.}

Our studies shows that regular and continuous observations of ozone and wind profiles in the urban boundary layer are mandatory to account for ozone surface variability. This is why the QUALAIR station (qualair.aero.jussieu.fr) was developed by SU in the center of Paris. The assimilation of ozone vertical profiles, PBL height and wind fields in chemical transport models will improve forecasts of "next-day" ozone pollution. While Doppler lidar, or urban canopy radar [12], are available to meet this goal, a new small size and autonomous UV DIAL lidar is still needed. It is currently under construction at LATMOS, using a diode pumped high repetition rate Nd-YAG laser and hollow core fiber for stimulated scattering.

\section{ACKNOWLEDGEMENTS}

This work was supported by SU and the OSU Ecce-TERRA. A. Klein and Elsa Dieudonné thesis were funded by Ministère de l'enseignement supérieur et de la recherche and supported by Ecole normale supérieure de Cachan (ENS ParisSaclay).

\section{REFERENCES}

[1] J.T. Sullivan, et al. Atmospheric Environment 158, 160-171 (2017)

[2] A. Klein, et al. Atmospheric Environment 167, 603-615.(2017)

[3] A. Klein, et al. Atmospheric Environment 197, 92-102 (2019)

[4] G. Ancellet and F. Ravetta Appl. Opt. 37(24), 5509-5521 (1998)

[5] G. Ancellet and F. Ravetta J. Environ. Monit. 5, 47-56 (2003)

[6] I. Veselovskii, et al. Atmos. Chem. Phys 16, 7013-7028 (2016)

[7] L. Menut, et al. Appl. Opt. 38, 945-954 (1999)

[8] F. Tack, et al., Atmospheric Measurement

Techniques 8 (6), 2417-2435 (2015)

[9] E. Dieudonné, et al. Geophysical Research

Letters 40(6), 1247-1251 (2013)

[10]J. Stutz,et al. Journal of Geophysical Research: Atmospheres 109(D12), D12306 (2004)

[11] S. Kuang et al. Atmospheric Environment 45(33), 6078-6084 (2011)

[12] A. Oude Nijhuis et al. BAMS 99 (11), 22752293 (2018). 